\title{
Changes of TNF- $\alpha$, PDGF and HA in nasal secretions and olfactory function of patients with chronic sinusitis before and after endoscopic sinus surgery
}

\author{
LINQI WEI* ${ }^{*}$ YONGHONG ZHANG ${ }^{*}$ and HUAZHANG TAN \\ Department of Otolaryngology-Head and Neck Surgery, Xiangyang No.1 People's Hospital, \\ Hubei University of Medicine, Xiangyang, Hubei 441000, P.R. China
}

Received January 25, 2018; Accepted August 2, 2018

DOI: $10.3892 /$ etm.2018.6611

\begin{abstract}
This study aimed to investigate the changes of tumor necrosis factor- $\alpha$ (TNF- $\alpha$ ), platelet-derived factor (PDGF), hyaluronic acid (HA) in nasal secretions and olfactory function in patients with chronic sinusitis before and after endoscopic sinus surgery. A total of 94 patients with chronic sinusitis treated at Xiangyang No.1 People's Hospital, Hubei University of Medicine (Xiangyang, China) from May 2016 to April 2017 were randomly divided into the control and observation groups, with 47 patients in each group. The observation underwent endoscopic sinus surgery, while the control group were treated with traditional extranasal surgery. The treatment efficacy of the two groups were compared 3 months after the treatment. A self-designed symptom questionnaire was used to evaluate the symptom scores. Enzyme-linked immunosorbent assay (ELISA) was used to detect the TNF- $\alpha$, PDGF and HA levels in nasal secretions. The olfactory function of the patients was evaluated by the standard T\&T olfactometry test. The life quality before and after the treatment was compared by using the SNOT-20 questionnaire. The treatment efficacy of the observation group was significantly higher than that of the control group $(\mathrm{P}<0.05)$. Both groups showed improved symptom scores after the treatment, while improvement in the observation group was more obvious $(\mathrm{P}<0.05)$. The observation showed significantly lower TNF- $\alpha$ level than the control group $(\mathrm{P}<0.05)$. One, four and eight weeks after treatment, the levels of PDGF and HA were significantly higher in the observation group than in the control group
\end{abstract}

Correspondence to: Dr Huazhang Tan, Department of Otolaryngology-Head and Neck Surgery, Xiangyang No.1 People's Hospital, Hubei University of Medicine, 15 Jiefang Road, Xiangyang, Hubei 441000, P.R. China

E-mail: tzu46m@163.com

${ }^{*}$ Contributed equally

Key words: chronic sinusitis, nasal endoscopic surgery, TNF- $\alpha$, platelet-derived factor, hyaluronic acid, olfactory function
$(\mathrm{P}<0.05)$. Both groups exhibited significantly improved olfactory function scores after treatment, and improvement in the observation group was more than that in the control group $(\mathrm{P}<0.05)$. After treatment, decreased scores of SNOT-20 in the observation group was more significant $(\mathrm{P}<0.05)$. Compared with traditional surgery, endoscopic surgery resulted in lighter postoperative inflammatory responses, better nasal mucosa repair, and more improved postoperative olfactory function.

\section{Introduction}

Chronic sinusitis is a common clinical otorhinolaryngology disease with a high incidence and recurrence rate in the general population. It is often accompanied by nasal polyps. The main clinical manifestations include headache, stuffy nose, snoring, loss of the sense of smell and runny nose (1). Chronic sinusitis is usually caused by chronic purulent inflammation of the sinus mucosa, causing eyesight changes and otitis media in patients when it is getting more severe (2). Clinically, the treatment of chronic sinusitis includes conservative and surgical treatment. The former often results in inadequate treatment and repeated recurrence. Although surgical treatment has better treatment effects, the traditional surgical treatment can easily lead to sinus and nasal injuries and intraoperative bleeding, resulting in poor recovery of nasal mucosal injury that interfere with recovery $(3,4)$. With the development of endoscopic technology, endoscopic sinus surgery is widely used clinically, and it can effectively promote the recovery of sinus function and improve the patient's life quality (5). Postoperative recovery of nasal mucosal injury involves tumor necrosis factor- $\alpha$ (TNF- $\alpha$ ), platelet-derived factor (PDGF), hyaluronic acid (HA) and other cytokines (6). In the present study, patients with chronic sinusitis were treated with different surgical methods, and the changes of their TNF- $\alpha$, PDGF, HA levels were studied to provide a basis for the effective treatment of chronic sinusitis.

\section{Materials and methods}

General Information. A total of 94 patients with chronic sinusitis treated at Xiangyang No.1 People's Hospital, Hubei University of Medicine (Xiangyang, China) from May 2016 
Table I. General information of the two groups of patients.

\begin{tabular}{lcccr}
\hline Items & Control $(\mathrm{n}=47)$ & Observation $(\mathrm{n}=47)$ & $\mathrm{t} / \chi^{2}$ & P-value \\
\hline Sex (Male/Female) & $19 / 28$ & $21 / 26$ & 0.044 & 0.835 \\
Age (years) & $45 \sim 70$ & $45 \sim 75$ & & 0.200 \\
Average (years) & $58.56 \pm 7.48$ & $58.85 \pm 6.57$ & 0.695 & 0.842 \\
Course of illness (years) & $5.63 \pm 3.46$ & $6.08 \pm 2.78$ & 1.171 & 0.489 \\
BMI $\left(\mathrm{kg} / \mathrm{m}^{2}\right)$ & $23.63 \pm 1.46$ & $23.27 \pm 1.52$ & & 0.245 \\
\hline
\end{tabular}

BMI, body mass index.

to April 2017 were selected for this study. Inclusion criteria were: i) Meeting the diagnostic criteria for chronic sinusitis (7); ii) having bilateral sinus lesions associated with nasal polyps; iii) being able to communicate properly; and iv) signing the informed consent. Exclusion criteria were: i) Previous history of sinusitis or nasal polyp surgeries, asthma or allergies; ii) oral administration of hormones or antibiotics in the past 1 month; and iii) topical nasal medication in the past 2 weeks or congenital absence of the sense of smell. The patients were randomly divided into the observation and control groups with 47 cases in each group. The two groups of patients had no statistically differences in their general information $(\mathrm{P}>0.05)$ (Table I).

This study was approved by the Ethics Committee of Xiangyang No.1 People's Hospital (Xiangyang, China). Signed written informed consents were obtained from the patients.

\section{Methods}

Treatment. The control group was treated by traditional surgery. Patients were instructed to take the supine position. After local infiltration anesthesia, the nasal polyps were removed with a nasal polyp snare. After the lesions were cleaned up, vaseline gauze was used to stop the bleeding and the gauze was removed 2 days later.

The observation group was treated by endoscopic sinus surgery. Antibiotics were given one week before the operation. After local infiltration and topical anesthesia, adrenaline cotton patches were used to deflate the nasal mucosa so as to fully expose the nasal passages. The Messerklinger technique was used to remove the nasal polyps. The maxillary and ethmoid sinus were opened to remove the lesions. Hemostatic gauze was used to stop the bleeding, and sodium chloride solution was used to rinse the wound. Vaseline gauze was removed 2 days later.

Both groups were given antibiotics for 3 days postope ratively. Paranasal sinuses and nasal cavity were cleaned and rinsed once a week after the operation.

Detection of TNF- $\alpha, P D G F$ and HA concentrations. Before and 1,4 and 8 weeks after surgery, small pieces of cotton were put into the patient's nasal passages for $10 \mathrm{~min}$ to collect the patient's nasal secretions (before cleaning). The cotton pieces were then put into $0.9 \%$ sodium chloride solution and the suspension was collected. After centrifugation at $4^{\circ} \mathrm{C}$ at $2,500 \mathrm{x} \mathrm{g}$ for $10 \mathrm{~min}$ (centrifugation radius $15 \mathrm{~cm}$ ), the supernatant was collected and stored in a $-80^{\circ} \mathrm{C}$ freezer. The levels of TNF- $\alpha$, PDGF and HA were detected by enzyme-linked immunosorbent assay (ELISA). All kits were provided by Dalian F.T.Z CREDIT
Chemical Technology Development Co., Ltd., (Liaoning, China). All operations strictly followed the manufacturer's instructions. A microplate reader (Elx800; BioTek Instruments, Inc., Winooski, VT, USA) was used to read the OD values at the wavelength of $450 \mathrm{~nm}$ and the concentrations of TNF- $\alpha$, PDGF and HA were calculated.

Olfactory function test. Solutions of phenylethyl alcohol, isovaleric acid, methylcyclopentenone, serotonin and undecylenic acid vinegar were made for the standardized T\&T olfactometry test. The kit was provided by Japan First Pharmaceutical Industry Co., Ltd. (Tokyo, Japan). Odorless filter paper was used to smear different odorants in various concentrations (8 concentrations) sequentially (at the interval of $30 \mathrm{sec}$ ) and placed close to the patient's noses $(1 \mathrm{~cm})$ for them to smell from 2 to 3 times. The detection and recognition thresholds of the patients were measured and the average olfactory thresholds were calculated.

Evaluation criteria. Treatment efficacy evaluation: i) Cured: disappearance of symptoms such as nasal congestion, headache and purulent nasal discharges; open sinus ostium without stenosis or occlusion; no purulent secretions. ii) Improved: significantly improved symptoms, edema or granulation in the sinus mucosa and a small amount of purulent secretions. iii) Ineffective: no improvement or worsening of various symptoms, sinus stenosis or atresia, obvious swelling, formation of polyps, large amount of purulent secretions (8).

A self-designed chronic sinusitis symptom questionnaire was used to obtain the symptom scores of the patients before and 1, 4 and 8 weeks after treatment. A scale of $0 \sim 3$ points $(0$ for no, 3 for severe) were used to evaluate patients' symptoms from several aspects including nasal congestion, purulent nasal discharge, headache, decreased sense of smell, and nasal or throat dryness. The final score was positively correlated with the severity of symptoms.

ELISA was used to detect the levels of TNF- $\alpha$, PDGF and HA in the nasal secretions of the patients before and 1, 4 and 8 weeks after treatment. The olfactory function was evaluated before and 1,2 and 3 months after treatment by the standard T\&T olfactometry test. The mean olfactory threshold of the five olfactory odorants was used to evaluate the olfactory function (9).

The SNOT-20 questionnaire was used to evaluate life quality of the patients before and after treatment (10). The scores were evaluated from 20 items at a scale from 0 to $3(0$, 
Table II. Comparison of the treatment efficacy n (\%).

\begin{tabular}{|c|c|c|c|c|c|}
\hline Groups & No. & Cured & Improved & Ineffective & Total effective rate \\
\hline Observation & 47 & $32(68.09)$ & $12(25.53)$ & $3(6.38)$ & $44(93.62)$ \\
\hline Control & 47 & $16(4.04)$ & $20(42.55)$ & $11(23.40)$ & $36(76.60)$ \\
\hline$\chi^{2}$ & & & & & 4.112 \\
\hline P-value & & & & & 0.042 \\
\hline
\end{tabular}

Table III. Changes of symptom scores of the two groups before and after treatment.

\begin{tabular}{|c|c|c|c|c|c|c|c|}
\hline \multirow[b]{2}{*}{ Groups } & \multirow[b]{2}{*}{ No. } & \multirow[b]{2}{*}{ Before surgery } & \multicolumn{3}{|c|}{ After surgery } & \multirow[b]{2}{*}{ F-value } & \multirow[b]{2}{*}{ P-value } \\
\hline & & & 1 week & 4 weeks & 8 weeks & & \\
\hline Observation & 47 & $11.85 \pm 1.13$ & $7.72 \pm 0.71^{\mathrm{a}}$ & $5.64 \pm 0.64^{\mathrm{a}}$ & $1.43 \pm 0.42^{\mathrm{a}}$ & 39.134 & $<0.001$ \\
\hline Control & 47 & $11.62 \pm 1.18$ & $9.64 \pm 0.68^{a}$ & $7.52 \pm 0.67^{\mathrm{a}}$ & $3.12 \pm 0.47^{\mathrm{a}}$ & 8.532 & 0.001 \\
\hline t-test & & 0.965 & 13.389 & 13.910 & 18.381 & & \\
\hline P-value & & 0.337 & $<0.001$ & $<0.001$ & $<0.001$ & & \\
\hline
\end{tabular}

${ }^{\mathrm{a} C}$ Compared with before surgery, $\mathrm{P}<0.05$.

Table IV. Comparison of the TNF- $\alpha$ levels of the two groups (pg/ml).

\begin{tabular}{|c|c|c|c|c|c|c|c|}
\hline \multirow[b]{2}{*}{ Groups } & \multirow[b]{2}{*}{ No. } & \multirow[b]{2}{*}{ Before surgery } & \multicolumn{3}{|c|}{ After surgery } & \multirow[b]{2}{*}{ F-value } & \multirow[b]{2}{*}{ P-value } \\
\hline & & & 1 week & 4 weeks & 8 weeks & & \\
\hline Observation & 47 & $93.43 \pm 3.24$ & $139.67 \pm 6.23^{\mathrm{a}}$ & $125.35 \pm 5.28^{\mathrm{a}}$ & $102.68 \pm 4.24^{\mathrm{a}}$ & 59.634 & $<0.001$ \\
\hline Control & 47 & $94.62 \pm 3.58$ & $157.27 \pm 6.64^{\mathrm{a}}$ & $139.47 \pm 5.36^{\mathrm{a}}$ & $111.83 \pm 4.78^{\mathrm{a}}$ & 38.572 & $<0.001$ \\
\hline t-test & & 1.690 & 13.252 & 12.866 & 9.818 & & \\
\hline P-value & & 0.094 & $<0.001$ & $<0.001$ & $<0.001$ & & \\
\hline
\end{tabular}

${ }^{\mathrm{a} C o m p a r e d}$ with before surgery, $\mathrm{P}<0.05$. TNF- $\alpha$, tumor necrosis factor- $\alpha$.

no, and 3, severe). Afterward, the five most important items were selected for more further analysis.

Statistical analysis. The data were processed by using the SPSS 19.0 (SPSS Inc., Chicago, IL, USA) software. The measurement data were expressed as mean \pm standard deviation (SD). Comparisons between the two groups were tested by t-test. The differences before and after treatment were tested by the paired t-test. The count data were expressed in terms of rate and tested by the $\chi^{2}$ test. Comparisons of parameters at different time-points One-way ANOVA test followed by post hoc test (Least Significant Difference). A P $<0.05$ was considered to indicate a statistically significant difference.

Comparison of the treatment efficacy of the two groups. The observation had a significantly higher total effective rate than the control group $(\mathrm{P}<0.05)$ (Table II).

Changes of symptoms scores of the two groups. One, four and eight weeks after treatment, the two groups had significantly improved symptom scores than before treatment. The observation group exhibited more improvement than the control group $(\mathrm{P}<0.05)$ (Table III).

Comparison of the TNF- $\alpha$ levels of the two groups. The TNF- $\alpha$ levels of both groups showed an increasing trend after surgery, and reached the peak 1 week after surgery. Compared with 1 week after surgery, the TNF- $\alpha$ levels were lower at 4 and 8 weeks after surgery. However, they were still higher than those before surgery. In addition, the TNF- $\alpha$ levels in the observation group were less increased than in the control group $(\mathrm{P}<0.05)$ (Table IV).

Comparison of the PDGF levels of the two groups. The PDGF levels of both groups showed an increasing trend after surgery, and reached the peak 1 week after surgery. Compared with 1 week after surgery, the PDGF levels were lower at 4 and 8 weeks after surgery. However, they were still higher than those before surgery. In addition, the PDGF levels in the observation group were more increased than in the control group (Table V). 
Table V. Comparison of the PDGF levels of the two groups (pg/ml).

\begin{tabular}{|c|c|c|c|c|c|c|c|}
\hline \multirow[b]{2}{*}{ Groups } & \multirow[b]{2}{*}{ No. } & \multirow[b]{2}{*}{ Before surgery } & \multicolumn{3}{|c|}{ After surgery } & \multirow[b]{2}{*}{ F-value } & \multirow[b]{2}{*}{ P-value } \\
\hline & & & 1 week & 4 weeks & 8 weeks & & \\
\hline Observation & 47 & $347.62 \pm 13.78$ & $3207.23 \pm 67.62^{\mathrm{a}}$ & $976.25 \pm 35.72^{\mathrm{a}}$ & $898.72 \pm 27.52^{\mathrm{a}}$ & 69.104 & $<0.001$ \\
\hline Control & 47 & $346.53 \pm 13.26$ & $2921.87 \pm 67.25^{\mathrm{a}}$ & $896.65 \pm 35.65^{\mathrm{a}}$ & $673.68 \pm 23.13^{\mathrm{a}}$ & 58.547 & $<0.001$ \\
\hline t-test & & 0.391 & 20.514 & 10.813 & 42.916 & & \\
\hline P-value & & 0.697 & $<0.001$ & $<0.001$ & $<0.001$ & & \\
\hline
\end{tabular}

${ }^{a}$ Compared with before surgery, $\mathrm{P}<0.05$. PDGF, platelet-derived factor.

Table VI. Comparison of the HA levels of the two groups (ng/l).

\begin{tabular}{|c|c|c|c|c|c|c|c|}
\hline \multirow[b]{2}{*}{ Groups } & \multirow[b]{2}{*}{ No. } & \multirow[b]{2}{*}{ Before surgery } & \multicolumn{3}{|c|}{ After surgery } & \multirow[b]{2}{*}{ F-value } & \multirow[b]{2}{*}{ P-value } \\
\hline & & & 1 week & 4 weeks & 8 weeks & & \\
\hline Observation & 47 & $846.82 \pm 23.57$ & $1438.56 \pm 36.63^{a}$ & $1275.47 \pm 29.36^{a}$ & $1197.56 \pm 23.74^{\mathrm{a}}$ & 79.605 & $<0.001$ \\
\hline Control & 47 & $845.75 \pm 23.25$ & $1322.64 \pm 36.28^{a}$ & $1106.36 \pm 29.27^{\mathrm{a}}$ & $973.52 \pm 17.16^{\mathrm{a}}$ & 68.724 & $<0.001$ \\
\hline t-test & & 0.222 & 15.415 & 27.965 & 52.435 & & \\
\hline P-value & & 0.825 & $<0.001$ & $<0.001$ & $<0.001$ & & \\
\hline
\end{tabular}

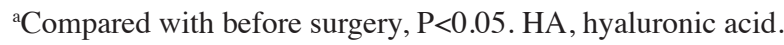

Table VII. Changes of olfactory function of the two groups of patients before and after treatment.

\begin{tabular}{|c|c|c|c|c|c|c|c|}
\hline Groups & No. & Before surgery & 1 month & 2 months & 3 months & F-value & P-value \\
\hline Observation & 47 & $3.85 \pm 0.43$ & $2.52 \pm 0.21^{\mathrm{a}}$ & $1.84 \pm 0.24^{\mathrm{a}}$ & $0.93 \pm 0.13^{\mathrm{a}}$ & 29.106 & $<0.001$ \\
\hline Control & 47 & $3.82 \pm 0.48$ & $3.14 \pm 0.38^{\mathrm{a}}$ & $2.52 \pm 0.37^{\mathrm{a}}$ & $1.92 \pm 0.15^{\mathrm{a}}$ & 22.683 & $<0.001$ \\
\hline t-test & & 0.319 & 9.790 & 10.571 & 34.193 & & \\
\hline P-value & & 0.750 & $<0.001$ & $<0.001$ & $<0.001$ & & \\
\hline
\end{tabular}

${ }^{\mathrm{a} C}$ Compared with before surgery, $\mathrm{P}<0.05$.

Comparison of HA levels of the two groups. The HA levels of both groups showed an increasing trend after surgery, and reached the peak 1 week after surgery. Compared with 1 week after surgery, the HA levels were lower at 4 and 8 weeks after surgery. However, they were still higher than those before surgery. In addition, the HA levels in the observation group were more increased than in the control group (Table VI).

Changes of olfactory function in the two groups 1, 2 and 3 months after treatment. The two groups of patients had significantly improved olfactory function when compared with that before treatment and the observation group improved more significantly $(\mathrm{P}<0.05)$ (Table VII).

Comparison of life quality scores of the two groups before and after treatment. After treatment, the SNOT-20 scores of both groups were significantly decreased when compared with those before treatment, and particularly those of the observation group were decreased more than those of the control group $(\mathrm{P}<0.05)$ (Table VIII).

\section{Discussion}

The causes of sinusitis are complex and include trauma, disorders in the respiratory ciliary system, gastroesophageal reflux, respiratory allergies and infections, anatomical abnormality of the sinuses and nasal cavity as well as systemic immunodeficiency (11). The nasal tissues of patients with chronic sinusitis usually develop edema under the long-term stimulation of inflammatory cytokines. At the same time, local aggregation of eosinophils occurs and a variety of cytokines and toxic proteins are released. The increase of the permeability of the nasal blood vessels results in plasma exudation, epithelial rupture and continuous proliferate. Extracellular matrix also proliferates and results in the formation of nasal polyps (12). About two-thirds of patients with chronic sinusitis also suffer olfactory dysfunction. The mechanism of olfactory 
Table VIII. Comparison of the life quality scores of the two groups.

\begin{tabular}{|c|c|c|c|c|c|c|c|c|}
\hline \multirow[b]{2}{*}{ Groups } & \multicolumn{2}{|c|}{ Twenty items after surgery (point) } & \multirow[b]{2}{*}{$\mathrm{t}$-test } & \multirow[b]{2}{*}{ P-value } & \multicolumn{2}{|c|}{ Most important 5 items (point) } & \multirow[b]{2}{*}{ t-test } & \multirow[b]{2}{*}{ P-value } \\
\hline & $\begin{array}{l}\text { Before } \\
\text { surgery }\end{array}$ & $\begin{array}{l}12 \text { weeks } \\
\text { after surgery }\end{array}$ & & & $\begin{array}{l}\text { Before } \\
\text { surgery }\end{array}$ & $\begin{array}{l}12 \text { weeks } \\
\text { after surgery }\end{array}$ & & \\
\hline Observation & $28.34 \pm 1.23$ & $9.05 \pm 1.04$ & 82.102 & $<0.001$ & $15.62 \pm 1.12$ & $5.12 \pm 1.02$ & 47.519 & $<0.001$ \\
\hline Control & $28.43 \pm 1.24$ & $15.47 \pm 1.18$ & 51.906 & $<0.001$ & $15.78 \pm 1.13$ & $9.76 \pm 1.04$ & 26.874 & $<0.001$ \\
\hline t-test & 0.353 & 27.982 & & & 0.689 & 21.837 & & \\
\hline $\mathrm{P}$-value & 0.725 & $<0.001$ & & & 0.493 & $<0.001$ & & \\
\hline
\end{tabular}

dysfunction caused by chronic sinusitis and nasal polyps is not yet fully understood (13). It is generally believed that the nasal mucosal edema and congestion obstruct olfactory sulcus, and make it difficult for odorant molecules to successfully reach the olfactory mucosa, resulting in olfactory disorders (14). The nasal and sinus cavities are narrow with complex anatomical structures, with characteristics of small and deep hole, which makes the treatment of chronic sinusitis more difficult. The disease has a serious impact on the quality of life of the patients.

Clinically, conservative treatment and surgery are two common ways to treat chronic sinusitis. Surgery can better treat the patients by improving and reconstructing sinus and nasal ventilation and drainage (15). The results of our study showed that after treatment, the total treatment effective rate of the observation group was significantly higher than that of the control group. After treatment, the symptom scores of both groups were significantly improved, and improvement in the observation group was more significant $(\mathrm{P}<0.05)$. This is because traditional sinus surgery can easily cause nasal and sinus damage as well as serious bleeding, which interferes with the postoperative recovery of the wounds. Endoscopic sinus surgery enables direct vision under the sinus endoscope. The structure and function of the paranasal sinuses and nasal cavity can be retained as much as possible, which benefits the rapid postoperative recovery of patients.

Patients with chronic rhinosinusitis usually undergo a longer period of recovery after surgery. During that time, the lesions will coexist with nasal mucosa regeneration, leading to edema and ductile inflammation. Eventually sinus mucosa epithelizes and patients recover (16). TNF- $\alpha$ is a critical and one of the earliest inflammatory mediators that may initiate and trigger inflammatory responses. It leads to a cascade of reactions that have a significant impact on the occurrence and prognosis of post-traumatic inflammation. It plays an important role in injuries caused by neutrophil aggregation (17). PDGF is an important mediator during the healing of wounds, which may stimulate cell proliferation, growth and promote the formation of granulation tissues (18). HA is a natural polymeric polysaccharide that is an important part of the tissue matrix. It has permeability, pseudoplasticity and high viscoelastity. Furthermore, it is important for wound healing (19). The results of this study showed that after treatment, the TNF- $\alpha$ levels in both groups were significantly higher than those before treatment, but the TNF- $\alpha$ level of the observation group was significantly lower than that of the control group.
The levels of PDGF and HA in both groups also increased significantly when compared with those before treatment, and the observation group had significantly higher PDGF and HA than the control group $(\mathrm{P}<0.05)$. This is because after surgery, a large number of PDGF is activated and its concentration continues to rise, promoting the proliferation and growth of a variety of cells and rapid healing of wounds. Compared with traditional surgical methods, the endoscopic sinus surgery is minimally invasive, and the faster healing of sinus mucosa is closely related to PDGF (18). During the postoperative mucosal epithelia repair process, secondary inflammation leads to elevated TNF- $\alpha$ level. Endoscopic sinus surgery causes less damage to normal mucosa and the degree of edema is reduced (20). During the early postoperative mucosal healing process, HA concentration rapidly increases and promotes the proliferation and migration of fibroblasts. The HA level was lower in the control group with traditional surgery than in the observation group with endoscopic sinus surgery. This is because endoscopic sinus surgery can clean the lesions within the sinuses and nasal cavity more thoroughly, and at the same time cause less damage to the nasal cilia. These effects benefit the deposition of collagen fibers and result in higher HA, promoting postoperative sinus mucosa healing (19).

The sense of smell is one of the human sensory functions, and recovery of the olfactory function after the treatment of chronic sinusitis patients directly affects the treatment efficacy (21). The results of this study showed that 1,2 and 3 months after treatment, the scores reflecting olfactory function in both groups were significantly improved when compared with those before treatment, and improvement in the observation group was more obvious $(\mathrm{P}<0.05)$. This may occur because the traditional surgical method is less thorough than the endoscopic sinus surgery in cleaning lesions. Thus, the suppressive state of olfactory sulcus caused by inflammation is not completely relieved, and recovery of the impaired olfactory cells and nerve fibers are not ideal. In addition, traditional surgery may cause greater damage to olfactory sulcus and lead to serious postoperative adhesions, disturbing the balance of the environment around the olfactory sulcus and increasing the difficulties for the odorant to reach the olfactory mucosa, and thus, resulting in poor olfactory recovery and decreased life quality of the patients.

In summary, endoscopic sinus surgery was more effective in the treatment of chronic sinusitis than traditional surgery, which was reflected by better olfactory function recovery of the patients. Clinically, nasal mucosa wound healing could be 
evaluated by detecting TNF- $\alpha$, PDGF and HA levels in the nasal secretions.

\section{Acknowledgements}

Not applicable.

\section{Funding}

No funding was received.

\section{Availability of data and materials}

The datasets used and/or analyzed during the present study are available from the corresponding author on reasonable request.

\section{Authors' contributions}

LW analyzed and interpreted the patient data and was a major contributor in writing the manuscript. YZ performed the experiment and participated in the design of the study. HT was also involved in the conception of the study. All authors have read and approved the final manuscript.

\section{Ethics approval and consent to participate}

This study was approved by the Ethics Committee of Xiangyang No.1 People's Hospital (Xiangyang, China). Signed written informed consents were obtained from the patients.

\section{Patient consent for publication}

Not applicable.

\section{Competing interests}

The authors declare that they have no competing interests.

\section{References}

1. Smith KA, Orlandi RR and Rudmik L: Cost of adult chronic rhinosinusitis: A systematic review. Laryngoscope 125: 1547-1556, 2015.

2. Tewfik MA, Latterich M, DiFalco MR and Samaha M: Proteomics of nasal mucus in chronic rhinosinusitis. Am J Rhinol 21: 680-685, 2007.

3. Chen FH, Deng J, Hong HY, Xu R, Guo JB, Hou WJ, Sun YQ, Lai YY, Li HB and Shi JB: Authors' Reply: Prognosis and risk in considering extensive vs functional endoscopic sinus surgery for chronic rhinosinusitis with nasal polyps and asthma. Am J Rhinol Allergy 31: 1, 2017.

4. Ragab SM, Lund VJ and Scadding G: Evaluation of the medical and surgical treatment of chronic rhinosinusitis: A prospective, randomised, controlled trial. Laryngoscope 114: 923-930, 2004.

5. Rudmik L, Soler ZM, Mace JC, Schlosser RJ and Smith TL: Economic evaluation of endoscopic sinus surgery versus continued medical therapy for refractory chronic rhinosinusitis. Laryngoscope 125: 25-32, 2015.
6. Lin DC, Chandra RK, Tan BK, Zirkle W, Conley DB, Grammer LC, Kern RC, Schleimer RP and Peters AT: Association between severity of asthma and degree of chronic rhinosinusitis. Am J Rhinol Allergy 25: 205-208, 2011.

7. Prince AA, Steiger JD, Khalid AN, Dogrhamji L, Reger C, Eau Claire S, Chiu AG, Kennedy DW, Palmer JN and Cohen NA: Prevalence of biofilm-forming bacteria in chronic rhinosinusitis. Am J Rhinol 22: 239-245, 2008.

8. Chen FH, Deng J, Hong HY, Xu R, Guo JB, Hou WJ, Sun YQ, Lai YY, Li HB and Shi JB: Extensive versus functional endoscopic sinus surgery for chronic rhinosinusitis with nasal polyps and asthma: A 1-year study. Am J Rhinol Allergy 30: 143-148, 2016.

9. Yumoto E, Minoda R, Hyodo M and Yamagata T: Causes of recurrent laryngeal nerve paralysis. Auris Nasus Larynx 29: 41-45, 2002.

10. Xu J, Park SJ, Park HS, Han R, Rha KS and Kim YM: Effects of triamcinolone-impregnated nasal dressing on subjective and objective outcomes following endoscopic sinus surgery. Eur Arch Otorhinolaryngol 273: 4351-4357, 2016.

11. Deroee AF, Naraghi M, Sontou AF, Ebrahimkhani MR and Dehpour AR: Nitric oxide metabolites as biomarkers for follow-up after chronic rhinosinusitis surgery. Am J Rhinol Allergy 23: 159-161, 2009.

12. Ho J, Bailey M, Zaunders J, Mrad N, Sacks R, Sewell W and Harvey RJ: Group 2 innate lymphoid cells (ILC2s) are increased in chronic rhinosinusitis with nasal polyps or eosinophilia. Clin Exp Allergy 45: 394-403, 2015.

13. Kato A: Immunopathology of chronic rhinosinusitis. Allergol Int 64: 121-130, 2015.

14. Shi JB, Fu QL, Zhang H, Cheng L, Wang YJ, Zhu DD, Lv W, Liu SX, Li PZ, Ou CQ, et al: Epidemiology of chronic rhinosinusitis: Results from a cross-sectional survey in seven Chinese cities. Allergy 70: 533-539, 2015

15. Bachert $C$, Zhang L and Gevaert P: Current and future treatment options for adult chronic rhinosinusitis: Focus on nasal polyposis. J Allergy Clin Immunol 136: 1431-1440, 2015.

16. Katotomichelakis M, Simopoulos E, Tripsianis G, Zhang N, Danielides G, Gouma P, Bachert C and Danielides V: The effects of smoking on quality of life recovery after surgery for chronic rhinosinusitis. Rhinology 52: 341-347, 2014.

17. Tokmadzić VS, Tsuji Y, Bogović T, Laskarin G, Cupurdija K, Strbo N, Koyama K, Okamura H, Podack ER and Rukavina D: IL-18 is present at the maternal-fetal interface and enhances cytotoxic activity of decidual lymphocytes. Am J Reprod Immunol 48: 191-200, 2002.

18. Fischer C, Doll J, Tanner M, Bruckner T, Zimmermann G, Helbig L, Biglari B, Schmidmaier G and Moghaddam A: Quantification of TGF-ß1, PDGF and IGF-1 cytokine expression after fracture treatment vs. non-union therapy via masquelet. Injury 47: 342-349, 2016.

19. Kilincoglu V, Yeter A, Servet E, Kangal M and Yildirim M: Short term results comparison of intraarticular platelet-rich plasma (prp) and hyaluronic acid (ha) applications in early stage of knee osteoarthritis. Int J Clin Exp Med 8: 18807-18812, 2015.

20. Agarwal BB, Nanavati JD, Agarwal N, Sharma N, Agarwal KA, Manish K, Saluja S and Agarwal S: Biomolecular inflammatory response to surgical energy usage in laparoscopic surgery: Results of a randomized study. Surg Endosc 30: 1733-1741, 2016.

21. Jiang RS, Lu FJ, Liang KL, Shiao JY, Su MC, Hsin CH and Chen WK: Olfactory function in patients with chronic rhinosinusitis before and after functional endoscopic sinus surgery. Am J Rhinol 22: 445-448, 2008.

This work is licensed under a Creative Commons Attribution-NonCommercial-NoDerivatives 4.0 International (CC BY-NC-ND 4.0) License. 